\title{
Skin Surface Topography and Texture Analysis of Sun-Exposed Body Sites in View of Sunscreen Application
}

\author{
Verena Korn ${ }^{a}$ Christian Surber ${ }^{b, d}$ Georgios Imanidis ${ }^{a, c}$ \\ anstitute of Pharmaceutical Technology, School of Life Sciences, University of Applied Sciences and Arts \\ Northwestern Switzerland, Muttenz, ${ }^{b}$ Department of Dermatology, University Hospital Basel, and ${ }^{\mathrm{c}}$ Department of \\ Pharmaceutical Sciences, University of Basel, Basel, and ${ }^{\mathrm{d}}$ Department of Dermatology, University Hospital Zurich, \\ Zurich, Switzerland
}

\section{Key Words \\ Skin surface topography - Skin texture - Roughness . \\ Sun-exposed body sites $\cdot$ Age $\cdot$ Sunscreen application}

\begin{abstract}
Background/Aims: To determine the roughness of the surface of human skin at highly sun-exposed anatomical sites in a wide age range in order to derive consequences for sunscreen application. Methods: The forehead, cheek, nose, shoulder, and dorsal hand of 4 age groups (0-9, 20-39, 4059 , and $>60$ years) were investigated by replica formation, and areal topography was determined by confocal chromatic imaging. The arithmetic mean height as a roughness parameter and the void volume of the surface profile were calculated. Results: Age and site had a significant effect on roughness. Both the dorsal hand and nose exhibited the greatest roughness over the age of 40 , and the forehead of the youngest age group exhibited the smallest roughness. Differentiation between sites progressed with age, whereas roughness increased significantly with age for the dorsal hand and nose but not for the other sites. The void volume was smaller than the volume corresponding to the typically recommended amount of sunscreen application except for the cases of largest roughness. Conclusions: Different site-
\end{abstract}

age combinations show significant variation of skin surface roughness. The application of sunscreen may in some instances need to be adjusted to take into account the increased roughness of highly sun-exposed anatomical sites.

(c) 2017 S. Karger AG, Basel

\section{Introduction}

The morphology of the skin surface has been studied extensively in the context of aging, disease, effect of sun exposure, and dermatological and cosmetic treatment. Skin micro-relief and wrinkles are manifestations of different etiology which in combination produce the overall skin roughness $[1,2]$. Roughness was found to be greater in aged compared to young skin at different anatomical sites including volar forearm, back of the hand, periorbital area, and temple [3-6], while results were conflicting for the lower leg [7]. Roughness was reported to vary significantly between different sites, being largest in the posterior neck and smallest in the upper back and lower leg, while only minor differences between genders and races were shown $[8,9]$. Surface topography was further used to assess the results of intervention on skin, for example, by moisturizing agents [10], antiaging products [6], laser

\section{KARGER}

E-Mail karger@karger.com

www.karger.com/spp (c) 2017 S. Karger AG, Basel

$1660-5527 / 17 / 0296-0291 \$ 39.50 / 0$
Georgios Imanidis

School of Life Sciences

University of Applied Sciences and Arts Northwestern Switzerland

Gründenstrasse 40, CH-4132 Muttenz (Switzerland)

E-Mail georgios.imanidis@ unibas.ch 
surgery [11], chemical irritants [12], and vitamin analogs [13].

The effect of chronic sun exposure has been evaluated based on skin surface topography. Photoaging was reported to exacerbate, in general, the alterations of relief caused by intrinsic aging $[1,2,14]$, and topographic findings were shown to correlate with self-reported sun exposure [15]. Chronic sun exposure increased the number and depth of furrows and anisotropy in the arms [16], while short-term intense exposure deepened primary furrows and flattened secondary furrows due to edema [17]. Finally, 1 study contended that an increase of roughness due to intrinsic aging was retarded by chronic exposure to sunlight [18].

Very few studies, however, have implicated skin roughness in the appropriate application of sunscreens. Since sun exposure evidently affects skin roughness, the question arises as to whether sunscreen application to the affected body sites should be adjusted to the altered surface topography. Recent reports have demonstrated that film thickness frequency distribution of applied sunscreen critically influences sun protection efficacy $[19,20]$. In those reports, the thickness of sunscreen was measured on an $8 \times 8 \mathrm{~mm}^{2}$ surface area of a skin substrate with a discretization step of $10 \mu \mathrm{m}$ in both directions of the surface. The occurrence of different thicknesses provided a distribution of thickness of the applied sunscreen layer that was shown to depend, as well as on the amount used, on the type of the sunscreen formulation and the application procedure. Substrate topography should also influence sunscreen thickness distribution. It has been suggested, for example, that a large volume of skin furrows has a negative impact on sunscreen film homogeneity [21] and that particulate UV filters accumulate overwhelmingly in skin furrows [22]. Furthermore, photodegradation of UV filters was found to depend on the applied amount and indirectly on the topography of the substrate [23]. Existing evidence, therefore, implies that skin topography should be taken into consideration for achieving the desirable sun protection factor (SPF).

For the noninvasive assessment of skin roughness, indirect replica-based techniques and direct in vivo techniques are in use $[24,25]$. Although fast and convenient direct methods that are appropriate for the clinical setting have been developed based on interference fringe profilometry and the use of CCD cameras [26-28], the preparation of replicas remains the most frequently used technique with a vast body of data available $[3-5,8,10,12,13$, $17,18,29-31]$. The advantages of the replica technique are simple and rapid sample preparation, reproducibility
Table 1. Definition of age groups of volunteers

\begin{tabular}{lll}
\hline Age group & Age range & Sex \\
\hline Group 1 & $0-9$ years & 3 female, 2 male \\
Group 2 & $20-39$ years & 5 female \\
Group 3 & $40-59$ years & 5 female \\
Group 4 & $>60$ years & 4 female, 1 male
\end{tabular}

and precision, and the possibility to store the replica for repeated measurements $[24,25]$.

The purpose of the present study was to determine the roughness of skin in 5 highly sun-exposed anatomical sites (sunny terraces) in human subjects of 4 different age groups in view of sunscreen application. The widest possible age range encompassing infants and elderly with a fine classification was employed in order to detect possible time evolution. Silicon replicas were prepared, and the topography was evaluated with a surface metrology instrument for noncontact confocal chromatic imaging [32]. This instrument allowed the analysis of a large surface area of the replica with high resolution and accuracy and provided 3D surface texture images and roughness parameters of areal topography. The topographic investigation is focused on anatomical sites whose surface roughness is likely influenced by exposure to sunlight and which should be regularly protected by sunscreen application. Differences of roughness obtained from this systematic study are statistically evaluated, and their consequence with respect to sunscreen application and sun protection efficacy of applied sunscreen is discussed. As roughness reflects the presence and extent of wrinkles and furrows on skin surface, the influence of these formations on the required sunscreen amount and the resulting sunscreen film thickness distribution, and ultimately surface coverage and sunscreen performance, is addressed.

\section{Materials and Methods}

Human Subjects

Twenty healthy Caucasian subjects aged 2-84 years took part in the study and were divided into 4 age groups of 5 subjects each (Table 1). Age group 1 ( $0-9$ years) consisted of 3 female and 2 male children, the youngest a boy aged 2 . Since teenagers often suffer from skin problems including acne which may interfere with skin surface characterization, this age group was excluded from the study. Age group 2 (20-39 years) and age group 3 (40-59 years) consisted of female volunteers. Age group 4 ( $>60$ years) included 1 male and 4 female subjects, the oldest a woman aged 84 . All volunteers or where applicable their parents provided their informed consent to the study. 
1

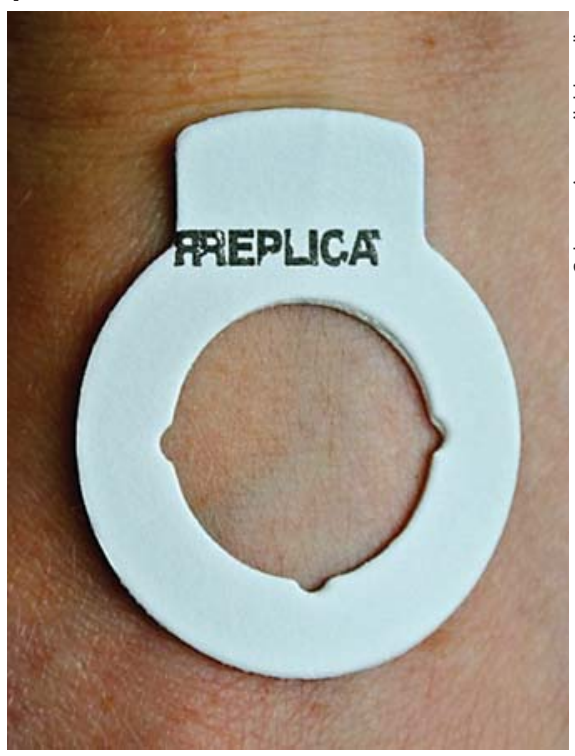

2

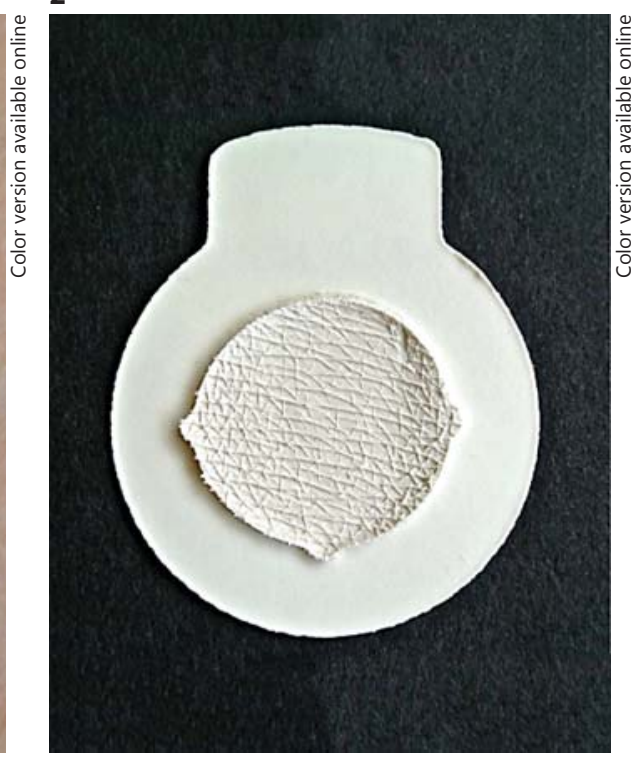

Fig. 1. Adhesive ring used as frame for imprinting placed on the dorsal side of the hand.

Fig. 2. Finished negative replica of skin surface. strument was equipped with a confocal chromatic probe operating on the basis of the white light chromatic aberration principle. The CL1 sensor probe was used with a theoretical axial resolution of $0.005 \mu \mathrm{m}$ and lateral resolution of $1.1 \mu \mathrm{m}$. A $3 \times 3 \mathrm{~mm}$ surface area was scanned with a discretization step of $10 \mu \mathrm{m}$. Depending on the maximal peak to valley range, the same field was scanned up to 8 times, each time with a $40-\mu \mathrm{m}$ shift in the $z$ direction. The final image consisted, therefore, of up to 8 single slices.

These slices were patched using AltiMap ${ }^{\circledR}$ software (Altimet), and the image was leveled to correct for a wide range curvature or tilt of the body site. Nonmeasured points arising predominantly from a slope angle of the specimen of greater than $43^{\circ}$ were filled in. The percentage of nonmeasured points of all measured replicas was below $3.5 \%$. The image of the negative imprint was turned upside down to convey a lifelike view of the skin surface.

The recorded micrographs were evaluated qualitatively on the basis of color-coded height image (Fig. 3) and quantitatively by means of the surface texture parameter (arithmetic mean height, $\mathrm{Sa})$. Sa gives the arithmetic mean height of the scale limited surface and is calculated as the arithmetic mean of the absolute of the ordinate values within a definition area, A, according to Equation 1 (geometrical product specifications, International Standard ISO 25178-2:2012):

$$
\mathrm{Sa}=\frac{1}{\mathrm{~A}} \iint_{\mathrm{A}}|\mathrm{z}(\mathrm{x}, \mathrm{y})| \mathrm{dx} \mathrm{dy} .
$$

Moreover, the void and the material volume of the topography of the sample were calculated with the same software.

\section{Statistical Analysis}

Statistical analysis was carried out with the Statgraphics Centurion software (Statpoint Technologies, Inc., Warrenton, VA, USA). Single classification analysis of variance (ANOVA) was performed for each age group $(0-9,20-39,40-59$, and $>60$ years $)$ separately to determine the significance of body site for Sa. Also, single classification ANOVA was carried out for each body site (forehead, cheek, nose, shoulder, and dorsal side of the left hand) 
Fig. 3. Example of recorded skin surface topography (back of hand, age group 0-9 years).

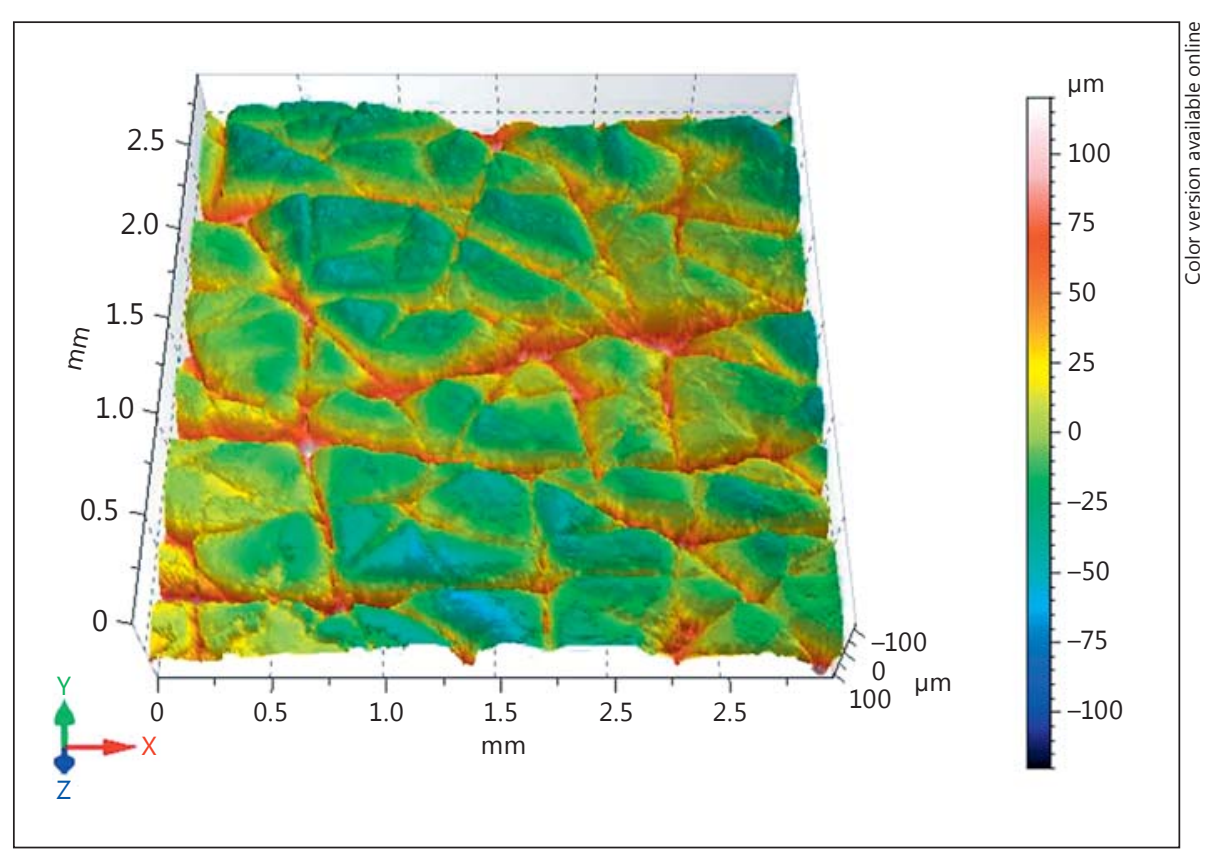

separately to determine the significance of age group for Sa. Finally, multiple sample comparison of all combinations of body site and age group and multiple range tests were performed to determine which Sa mean values of body site and age group were significantly different from which others. This yielded homogeneous groups of means based on the Fisher least significant difference procedure. Homogeneity of variances was checked by the Levene test. Statistical significance was defined as $\mathrm{p}<0.05$.

\section{Results and Discussion}

\section{Topography}

Representative images of skin surface topography of all anatomical sites of 1 subject from each age group are shown in Figure 4. Average values and standard deviations (SD) of the determined surface texture parameter Sa are given in Table 2 and Figure 5. A large difference of surface topography and Sa among age groups and body sites is evident, with the height parameter Sa ranging roughly between 10 and $45 \mu \mathrm{m}$. The result of the multiple range tests is shown in Figure 6.

A statistically significant influence of the anatomical site on Sa was found for every age group except for group 2 (20-39 years). The significance for group 1 ( $0-9$ years) was with $p<0.05$ weaker than for groups 3 and 4 (40-59 and $>60$ years, respectively), which yielded $p<0.01$. This suggests that differentiation of surface texture between sites progresses with age. Sa was highest in the dorsal side of the hand of groups 3 and 4 , indicating larger roughness of this site (Fig. 5, 6). The other sites could not be validly ranked in terms of Sa for any of the age groups, which might be because of the rather small size of the sample. A typical polygonal mesh structure of the skin surface is clearly seen in the dorsal side of the hand and less clearly in the shoulder but not in the other investigated body sites (Fig. 4).

A highly significant effect of age on the height parameter Sa was found for the nose and the dorsal side of the hand $(p<0.01)$ but not for the other anatomical sites. Sa of the nose and hand was generally greater for the 2 older age groups, indicating an increasing roughness with advancing age (Fig. 5, 6). For the dorsal side of the hand, a steady increase of the surface roughness with age could be observed. Inspection of the images of Figure 4 indicates greater height differences in the topographic skin profile of the older age groups, implying the strong presence of furrows, wrinkles, and deep pores. Also, the polygonal mesh structure of the hand was seen to be coarsening and deepening in the older age groups. According to the present results, an increase of skin roughness becomes notable above the age of 40 . This might be attributed to aging due to continuous sun exposure but also to other physiological factors. Interestingly, increased roughness did not apply equally to all anatomical sites. No difference, for example, was found for the shoulder, which is normally subject to less sunlight exposure than the face and hands. 


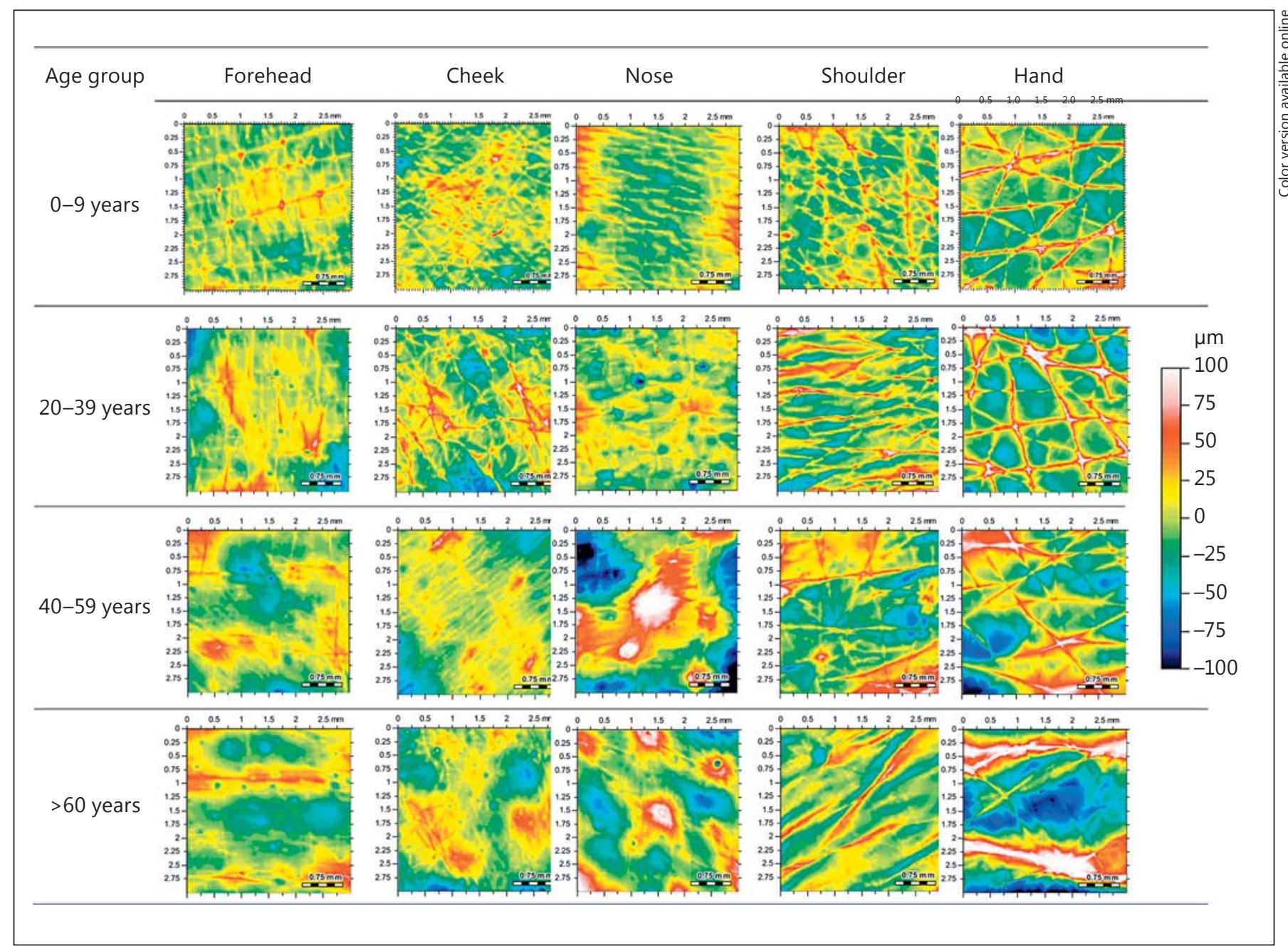

Fig. 4. Typical skin surface topography of different body sites and age groups. Recorded images of 1 subject from each age group are shown. Color-coded height ( $z$ amplitude) is given by the scale bar on the right (color in online version only). Zero height was adjusted for all images to the mean plane of the measured surface. Different colors denote peaks and pits.

Table 2. Mean skin surface texture parameter Sa for 4 age groups and 5 anatomical sites

\begin{tabular}{llllll}
\hline Age group & Forehead & Cheek & Nose & Shoulder & Hand \\
\hline Group 1: $0-9$ years & $10.63 \pm 1.9^{\mathrm{a}}$ & $15.92 \pm 3.71$ & $16.31 \pm 5.72$ & $21.38 \pm 8.43$ & $22.99 \pm 3.09$ \\
Group 2: 20 -39 years & $18.82 \pm 4.29$ & $23.09 \pm 9.95$ & $16.20 \pm 6.86$ & $17.25 \pm 3.41$ & $23.93 \pm 2.94$ \\
Group 3: $40-59$ years & $20.05 \pm 10.10$ & $20.63 \pm 9.23$ & $33.84 \pm 4.87$ & $21.54 \pm 4.79$ & $34.28 \pm 6.45$ \\
Group 4: $>60$ years & $21.08 \pm 3.64$ & $28.65 \pm 14.29$ & $26.13 \pm 8.22$ & $22.54 \pm 5.25$ & $46.53 \pm 15.66$ \\
\hline
\end{tabular}

Data are expressed as mean $\pm \mathrm{SD}$ (in micrometers). $n=5$ per group. ${ }^{\mathrm{a}} n=4$. 


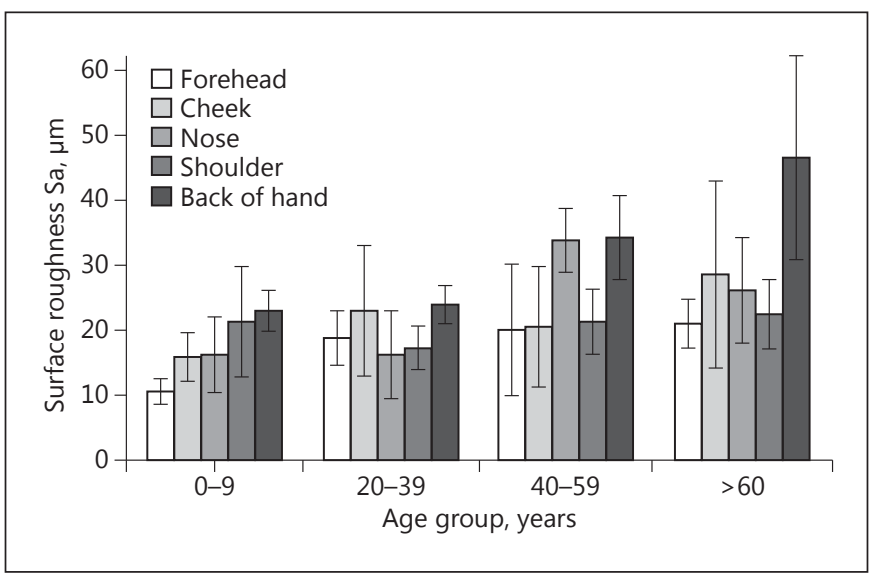

Fig. 5. Surface texture parameter Sa for different age groups and anatomical body sites. Columns and bars show mean and SD, respectively. $n=5$ except for forehead, age group 0-9 $(n=4)$.

These results are in general agreement with previous observations which involved the anatomical site at the eye corner [4] and 2 sites, forearm and back of hand [5] or forearm and temple, in 2 age groups [3]. A study differentiating only between young and aged adults but including numerous sites (lower leg and thigh, abdomen, lower and upper back, dorsal, volar forearm and upper arm, and periorbital area) concluded that the age effect on roughness is dependent on site, although some confounding between intrinsic aging and photoaging occurred [8]. The relative influence of intrinsic aging compared to photoaging for stratum corneum characteristics has been debated in the literature $[14,16,18]$. In any case, the interaction between age and the relevant body sites in terms of increased skin roughness seems essential in view of sunscreen application.

In the multiple range tests (Fig. 6), 66 pairs of mean Sa values exhibited a statistically significant difference. These involved the dorsal hand side of age groups 3 and 4 , which had a greater surface roughness that most of the other body sites of all age groups. Further, the forehead of age group 1 showed a smaller roughness than many of the other body sites of the other age groups. Finally, the nose of age group 3 exhibited a greater roughness than most other sites of all age groups. Together, the above-mentioned 4 cases accounted for 58 of the 66 detected significant roughness differences among the various body site and age group combinations. The large roughness of the cheek and nose of age group 4 was responsible for the remaining significant differences. Hence, although a significant influence of body site and age on skin roughness was detected in this study, the vast majority of the differentiation of surface texture can be ascribed to few cases. These implicate the particularly smooth surface of the forehead of young children, the wrinkled hands of older adults, and the deeply porous surface of the nose and, partly, the cheek of older adults.

\section{Consequences for Sunscreen Application}

In this study, anatomical body sites regularly exposed to the sun were investigated. These sites are therefore susceptible to sunburn and are subject to skin aging as a result of solar irradiation. Also, sunscreen application on a daily basis is recommended for these body sites possibly in combination with a skin care product. The amount of applied sunscreen and the resulting film thickness of the product on the skin are crucial for sun protection. In particular, the role of film thickness uniformity for sunscreen efficacy has been discussed extensively $[33,34]$. In recent studies, thickness frequency distribution of the sunscreen layer applied to the skin was measured and shown to be decisive for the performance of sunscreens [19]. The distribution of film thickness of equal amounts of applied sunscreen was found to vary widely depending on the structure with respect to the oil and water phase and the rheological properties of the sunscreen formulation. Model calculations using measured film thickness frequency distribution yielded SPF of different sunscreen formulations containing the same composition of UV filters that agreed well with experimental in vitro SPF [20]. That study also established that increased frequency of small film thickness and a very small surface area of uncovered skin seriously compromise sun protection efficacy.

Topography of skin may influence the distribution of the applied product. Thus, high roughness entailing deep wrinkles, furrows, and pores may cause accumulation, especially of low viscosity sunscreen formulations, leading to an irregular film and potentially leaving peaks and high areas of the skin surface virtually uncovered. To quantitatively ascertain this effect of roughness, the volume of voids of skin surface topography is put in relation to the commonly recommended sunscreen application amount of $2 \mathrm{mg} / \mathrm{cm}^{2}$. The volume of the voids, v, can be estimated from the following equation using the determined parameter Sa:

$$
\mathrm{v}=(2 \times \mathrm{Sa} / 10) \times \mathrm{vf}
$$

where $\mathrm{v}$ is expressed in $\mathrm{mm}^{3} / \mathrm{cm}^{2}$, and $\mathrm{vf}$ is the void volume fraction of the skin topography. Since Sa is the arithmetic mean of the absolute of the ordinate (the $z$ direction 
Fig. 6. Multiple comparisons between Sa means of body sites and age groups by multiple range tests. Groups 1, 2, 3, and 4 correspond to $0-9,20-39,40-59$, and $>60$ years, respectively. Statistically significant difference between a pair is denoted by a red (dark) square (color in online version only). $p<0.05$.

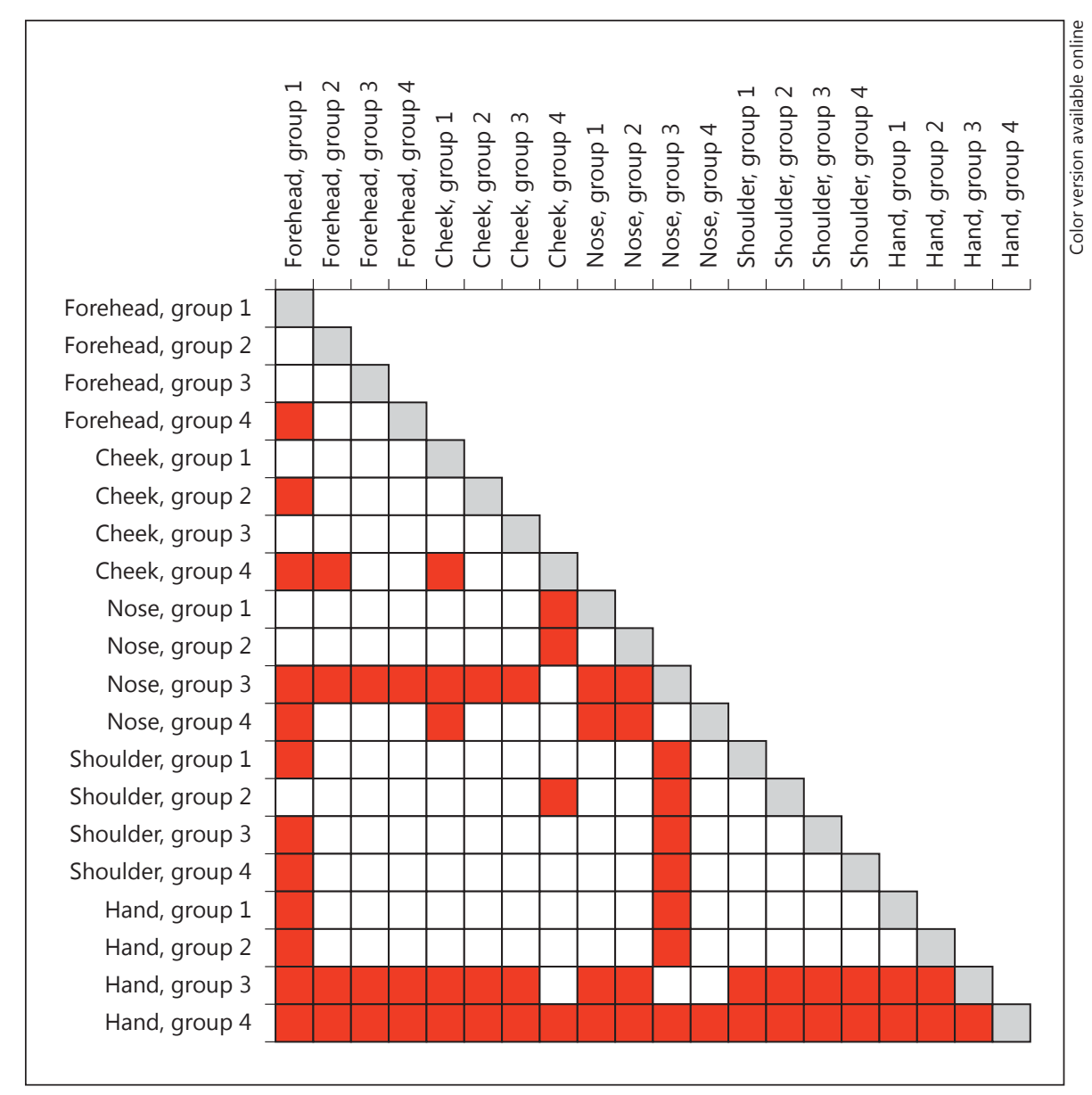

value of surface texture), this parameter corresponds to the height of a rectangular prism with the same volume as the peaks and valleys of the surface under consideration. Further, as $\mathrm{Sa}$ is measured from the mean (reference) line of the profile, the factor " 2 " is used to obtain the total volume. Finally, the factor " 10 " serves the adjustment of units.

Topographic measurements of all samples yielded an average void volume fraction, vf, of 0.36 (SD 0.095). The $\mathrm{vf}$ was found to be independent of Sa (graph not shown). Therefore, for the samples with the smallest and largest roughness corresponding to Sa of 10.63 and $46.53 \mu \mathrm{m}$, respectively, void volumes of 0.765 and $3.35 \mathrm{~mm}^{3} / \mathrm{cm}^{2}$, respectively, are estimated. Assuming an approximate density of sunscreen formulations of $10^{3} \mathrm{~kg} / \mathrm{m}^{3}$ or $1 \mathrm{mg} /$ $\mathrm{mm}^{3}$, it is obvious that the recommended application amount of sunscreen of $2 \mathrm{mg} / \mathrm{cm}^{2}$ exceeds the void volume of small roughness skin surface, while it is not sufficient to fill the void volume of high roughness skin surface. Using Equation 2, $2 \mathrm{mg} / \mathrm{cm}^{2}$ is found to correspond to the void volume of skin surface with roughness parameter $\mathrm{Sa}$ of approximately $28 \mu \mathrm{m}$. It is evident from Figure 5 (and Table 2) that the majority of the studied skin surfaces had, on average, roughness smaller than this margin except for the dorsal side of the hand of the 2 oldest age groups, the nose of age group 3, and the cheek of age group 4.

This discussion is based on the assumption that film formation on the surface of the skin is completed upon application as a result of mechanical "rubbing out". Theoretically, however, leveling out of the film surface may on the one hand occur by viscous flow, and on the other hand Marangoni effects due to surface tension gradients brought about by evaporation of volatile components of the film may lead to convective flow out of deep furrows. A very interesting paper [35], using in silico fluid dynamics for different rheological properties of the applied sunscreen, demonstrated that these mechanisms do not contribute to film formation to any great extent. They therefore concluded that film formation is the result of the 
rubout process during application, which causes the void volume of the skin surface to be filled with sunscreen.

The present study shows that at a young age surface roughness of highly sun-exposed anatomical sites does not vary significantly between the sites. Also, all sites of these age groups seem to be uncritical with respect to the recommended amount of applied sunscreen. For aged skin, on the other hand, increased roughness of some body sites can be of consequence for sunscreen application. These are the dorsal side of the hand and the face (the nose and to a lesser extent the cheeks). For these cases the application of a larger amount of sunscreen may be recommended. Notably, this does not apply to the shoulder. For everyday life situations, our observations further aggravate the frequently observed phenomenon that the necessary amount of sunscreen needed to deliver the labeled SPF is not reached. With the knowledge of the behavioral aspects of sunscreen use and its contingent nature [36], explicit and targeted information for these age groups for increased amount and/or frequency of application may be required. However, given the shortcomings of commercial high SPF sunscreens with respect to sensory characteristics [35], formulations with improved sensory profile are needed to assist compliance with recommended product use.

Besides the required sunscreen amount, surface roughness could have further implications for sunscreen application. Previous results [19] have shown that a fairly broad frequency distribution of film thickness is obtained when sunscreen is applied to a low roughness skin substrate consisting of isolated epidermis. The effect of substrate roughness on film irregularity has not been systematically investigated. However, it is considered likely that, depending on formulation properties of the sunscreen, increased skin roughness gives rise to greater film irregularity, further compromising sunscreen performance. Moreover, evaporation of volatile components quickly reduces the amount of sunscreen formulation remaining on the skin surface to less than half. To maintain adequate coverage, formulations with good film-forming properties and/or increased viscosity will be necessary to best mimic the contour of the surface instead of merely filling up the void volume of skin surface. This requirement is likely to be more important for high roughness skin sites.

\section{Conclusion}

Both anatomical site and age are found to have a statistically significant effect on roughness of highly sun-exposed body sites. This is accompanied by differences in visual appearance. The dorsal hand side, the nose, and in part the cheek had a greater roughness than the other body sites, with this difference becoming apparent in the elderly but not in young skin. At a young age no differentiation with respect to sunscreen application need be made between different body sites. Also, the generally recommended application amount of $2 \mathrm{mg} / \mathrm{cm}^{2}$ appears to be adequate. In advanced age, however, high roughness sites may require enhanced sunlight protection consisting of increased amount and improved formulation properties of sunscreen.

\section{Acknowledgment}

Funding by the Gebert Rüf Stiftung is thankfully acknowledged.

\section{Statement of Ethics}

All volunteers, or where applicable their parents, provided their informed consent to the study.

\section{Disclosure Statement}

The authors disclose no conflicts of interest. No funding other than that stated in the acknowledgment was received for this research.

\section{References}

1 Piérard GE, Uhoda I, Piérard-Franchimont C: From skin microrelief to wrinkles. An area ripe for investigation. J Cosmet Dermatol 2004;2:21-28.

2 Quatresooz P, Thirion L, Piérard-Franchimont C, Piérard GE: The riddle of genuine skin microrelief and wrinkles. Int J Cosmet Sci 2006;28:389-395.
3 Lagarde JM, Rouvrais C, Black D: Topography and anisotropy of the skin surface with ageing. Skin Res Technol 2005;11:110-119.

4 Akazaki S, Nakagawa H, Kazama H, Osanai O, Kawai M, Takema Y, Imokawa G: Age-related changes in skin wrinkles assessed by a novel three-dimensional morphometric analysis. Br J Dermatol 2002;147:689-695.
5 Li L, Mac-Mary S, Marsaut D, Sainthillier JM, Nouveau S, Gharbi T, de Lacharriere O, Humbert P: Age-related changes in skin topography and microcirculation. Arch Dermatol Res 2006;297:412-416.

6 Jacobi U, Chen M, Frankowski G, Sinkgraven R, Hund M, Rzany B, Sterry W, Lademann J: In vivo determination of skin surface topography using an optical 3D device. Skin Res Technol 2004;10:207-214. 
7 Corcuff P, Leveque JL, Grove GL, Kligman AM: The impact of aging on the microrelief of peri-orbital and leg skin. J Soc Cosmet Chem 1987;82:145-152.

8 Manuskiatti W, Schwindt DA, Maibach HI: Influence of age, anatomic site and race on skin roughness and scaliness. Dermatology 1998;196:401-407.

9 Chinn HD, Dobson RL: The topographic anatomy of human skin. Arch Dermatol 1964; 89:267-273.

10 Fischer TW, Wigger-Alberti W, Elsner P: Assessment of 'dry skin': current bioengineering methods and test designs. Skin Pharmacol Appl Skin Physiol 2001;14:183-195.

11 Friedmann PM, Skover GR, Payonk G, Kauvar ANB, Geronemus RG: 3D in-vivo optical skin imaging for topographical quantitative assessment of non-ablative laser technology. Dermatol Surg 2002;28:199-204.

12 Schwindt DA, Wilhelm KP, Miller DL, Maibach HI: Cumulative irritation in older and younger skin: a comparison. Acta Derm Venereol 1998;78:279-283.

13 Griffiths CEM, Maddin S, Wiedow O, Marks R, Donald AE, Kahlon G: Treatment of photoaged skin with a cream containing $0.05 \%$ isotretinoin and sunscreens. J Dermatol Treat 2005;16:79-86.

14 Tagami H: Functional characteristics of the stratum corneum in photoaged skin in comparison with those found in intrinsic aging. Arch Dermatol Res 2008;300:S1-S6.

15 Weiler L, Knight JA, Vieth R, Barnett H, Wong A: Comparison of self-reported sun exposure with two methods of cutaneous microtopography. Am J Epidemiol 2007;165:222230.

16 Corcuff P, Francois AM, Leveque JL, Porte G: Microrelief changes in chronically sun-exposed human skin. Photodermatol 1988;5: 92-95.

17 Mazzarello V, Cametti M, Leone G, Iacovelli P, Ena P, Leigheb G: Analysis of the microto- pography of the skin by silicone replicas after repeated exposure to actinic radiation at high altitudes. J Eur Acad Dermatol Venereol 2001;15:224-228.

18 Edwards C, Heggie R, Marks R: A study of differences in surface roughness between sunexposed and unexposed skin with age. Photodermatol Photoimmunol Photomed 2003;19: 169-174.

19 Sohn M, Heche A, Herzog B, Imanidis G: Film thickness frequency distribution of different vehicles determines sunscreen efficacy. J Biomed Optics 2014;19:115005.

20 Sohn M, Herzog B, Osterwalder U, Imanidis G: Calculation of sun protection factor of sunscreens with different vehicles using measured film thickness distribution - comparison with the SPF in vitro. J Photochem Photobiol B 2016;159:74-81.

21 Gebauer V, Weigmann H-J, Schanzer S, Meinke MC, Vergou T, Sterry W, Lademann $\mathrm{J}$ : Influence of skin aging effects on the skin surface profile and the correlated distribution of topically applied sunscreens. J Biophotonics 2012;5:274-282.

22 Adlhart C, Baschong W: Surface distribution and depths profiling of particulate organic UV adsorbers by Raman imaging and tape stripping. Int J Cosmet Sci 2011;33:527-534.

23 Miura Y, Hirao T, Hatao M: Influence of application amount on sunscreen photodegradation in in vitro sun protection factor evaluation: proposal of a skin-mimicking substrate. Photochem Photobiol 2012;88:475-482.

24 Tchvialeva L, Zeng H, Markhvida I, McLean DI, Lui H, Lee TK: Skin roughness assessment; in Campolo D (ed): New Developments in Biomedical Engineering. Vukovar, In-Teh, 2010, pp 341-358.

25 Rosén B.-G, Blunt L, Thomas TR: On in-vivo skin topography metrology and replication techniques. J Phys Conf Ser 2005;13:325-329.

26 Bloemen MC, van Gerven MS, van der Wal MBA, Verhaegen PDHM, Middelkoop E: An objective device for measuring surface roughness of skin and scars. J Am Acad Dermatol 2011;64:706-715.

27 Sparavigna A, Marazzato R: An image processing analysis of skin textures. Skin Res Technol 2010;16:161-167.

28 Lagarde JM, Rouvrais C, Black D, Diridollou S, Gall Y: Skin topography measurements by interference fringe projection: a technical validation. Skin Res Technol 2001;7:112121

29 Lévêque JL: EEMCO guidance for the assessment of skin topography. J Eur Acad Dermatol Venereol 1999;12:103-114.

30 Corcuff P, Piérard GE: Skin imaging: state of the art at the dawn of the year 2000; in Elsner $\mathrm{P}$, et al (eds): Skin Bioengineering: Techniques and Applications in Dermatology and Cosmetology. Basel, Karger, 1998, vol 26, pp $1-11$.

31 Forslind B: Replication techniques for dry and wet biological surfaces. Scanning Microsc 1999;13:133-139.

32 Browke MA, Akinyemi O, Boyde A: Confocal surface profiling utilizing chromatic aberration. Scanning 1992;14:145-153.

33 Ferrero L, Pissavini M, Marguerie S, Zastrow L: Efficiency of a continuous height distribution model of sunscreen film geometry to predict a realistic sun protection factor. J Cosmet Sci 2003;54:463-481.

34 Ferrero L, Pissavini M, Doucet O: How a calculated model of sunscreen film geometry can explain in vitro and in vivo SPF variation. Photochem Photobiol Sci 2010;9:540-551.

35 Vollhardt J, Schoop R, Janssen A, MendrokEdinger C, Klock J, Baltussen M, Oosterlinck F: The future of sunscreens: what lies beyond SPF 50+? SOFW J 2015;141:42-48.

36 Diffey B: Behavioral aspects of sunscreen use. 2015. https://www.carecreations.basf.com/ science-excellence/studies-articles/news-detail/2015/8/12/behavioral-aspects-of-sunscreen-use (accessed August 2016). 